\title{
Familial Translocation $t(6 ; 20)(p 21 ; p 13)$ Resulting in Partial Trisomy 6p and Partial Monosomy 20p: Report of a New Case and Review of the Literature
}

\author{
A.L. Berner ${ }^{a} \quad$ S. Bağci ${ }^{a} \quad$ E. Wohlleber ${ }^{b} \quad$ E. Engels ${ }^{b} \quad$ A. Müller ${ }^{a} \quad$ P. Bartmann ${ }^{a}$ \\ R.G. Weber ${ }^{b, c} \quad$ H. Reutter ${ }^{a, b}$ \\ ${ }^{a}$ Department of Neonatology, Children's Hospital, and b Institute of Human Genetics, University of Bonn, Bonn, and \\ 'Department of Human Genetics, Hannover Medical School, Hannover, Germany
}

\section{Key Words}

Familial translocation - Partial monosomy 20p •

Partial trisomy $6 p \cdot$ Unbalanced

\begin{abstract}
Carriers of completely balanced chromosomal translocations have all necessary genetic information. Nevertheless, because of the possibility of maldistribution during gametogenesis, they are at increased risk for infertility, miscarriage, stillbirth or having a child with congenital anomalies including mental retardation. As postnatal clinical reports are infrequent, prediction of clinical course for specific unbalanced karyotypes diagnosed during pregnancy remains difficult. Here, we report the 6 th case of partial trisomy $6 p$ and partial monosomy $20 \mathrm{p}$ due to an unbalanced adjacent- 1 segregation of the rare familial translocation $\mathrm{t}(6 ; 20)(\mathrm{p} 21 ; \mathrm{p} 13)$. We give a thorough clinical description of the present case, demonstrating broad phenotypic overlap with the 5 previously published cases reviewed here, providing important data on postnatal outcome.

Copyright $\odot 2012$ S. Karger AG, Basel
\end{abstract}

Reciprocal translocations are found in about 1 out of 625 human newborns [Oliver-Bonet et al., 2002]. They are caused by an exchange of material between nonhomologous chromosomes, often without loss of relevant genetic information, and thus do not frequently affect the health of the carrier. However, carriers of balanced reciprocal translocations are at increased risk of having gametes with unbalanced chromosome translocations, leading to miscarriage or abnormal embryonic, fetal and postnatal development. Genetic counseling of couples carrying a balanced translocation can be challenging because, although there are figures predicting the risk of having a liveborn aneuploid child based on the chromosomal regions involved in the translocation, only a few reports are available of the postnatal clinical course in children who carry unbalanced translocations which may result from such pregnancies.

Here, we report the 6 th case with partial trisomy $6 p$ and partial monosomy $20 \mathrm{p}$ due to a familial reciprocal translocation $\mathrm{t}(6 ; 20)(\mathrm{p} 21 ; \mathrm{p} 13)$ in a German kindred. Cytogenetic workup of the case, a thorough phenotypic description and the extended family history are presented. We demonstrate broad phenotypic overlap with the 5 previously described cases with identical unbalanced karyotypes by Therkelsen et al. [1971] and Breuning et al.

\begin{tabular}{|c|c|}
\hline KARGER & $\begin{array}{l}\text { (c) } 2012 \text { S. Karger AG, Basel } \\
1424-8581 / 12 / 1364-0308 \$ 38.00 / 0\end{array}$ \\
\hline $\begin{array}{l}\text { Fax +41 } 613061234 \\
\text { E-Mail karger@karger.ch } \\
\text { www.karger.com }\end{array}$ & $\begin{array}{l}\text { Accessible online at: } \\
\text { www.karger.com } / \mathrm{cgr}\end{array}$ \\
\hline
\end{tabular}


[1977]. The importance of detailed clinical descriptions of patients carrying such rare unbalanced translocations is stressed to provide couples with well-founded information in genetic counseling.

\section{Material and Methods}

\section{Present Case}

The present case (fig. 1, III.11) is the 1st liveborn child of healthy unrelated parents. At his birth, his mother (fig. 1, II.3) was 29 years old. Before, his mother had 2 spontaneous abortions (fig. 1, III.7 and III.8) in the 1st trimester, 1 miscarriage at 18 weeks of gestation (fig. 1, III.9), and 1 stillbirth at 22 weeks of gestation (fig. 1, III.10). The mother's elder sister had 4 spontaneous abortions (fig. 1, III.1-4), 1 stillbirth at the end of the 2nd trimester (fig. 1, III.5) and 1 healthy liveborn son (fig. 1, III.6). Both sisters sought genetic counseling and were found to carry the same familial balanced translocation $\mathrm{t}(6 ; 20)(\mathrm{p} 21.3 ; \mathrm{p} 13)$. During pregnancy with the present case, amniocentesis was carried out showing an unbalanced translocation resulting in trisomy $6 \mathrm{p} 25-\mathrm{p} 21.3$ and partial monosomy 20p13. Prenatal ultrasound studies indicated severe retrognathia. Although during prenatal genetic counseling the risk of a bad outcome was clearly pointed out, the couple decided to continue the pregnancy. Due to premature rupture of the membranes and signs of beginning chorioamnionitis, the propositus was delivered at $31+6$ weeks of gestation. Because of respiratory distress, he was admitted to the neonatal intensive care unit. His weight was $1,490 \mathrm{~g}$ (20th percentile), his length 42 $\mathrm{cm}$ (30th percentile) and his head circumference $28.5 \mathrm{~cm}$ (15th percentile). Physical examination revealed wide fontanelles with wide sagittal suture, prominent forehead, flat occiput, hypotelorism, ptosis, blepharophimosis, high nasal bridge, long philtrum, severe retrognathia, low set ears, sacral dimple and very fair skin (fig. 2), while neither hands nor feet showed any abnormalities. Sono- and radiographic studies revealed a small atrial septal defect (secundum type) and hyperechogenic dense kidneys. Proteinuria was detected at the age of 2 months as well as impaired hearing. The ophthalmological examination revealed no further abnormalities. At the age of 3 months the propositus had breathing difficulties due to severe retrognathia and microstomia, also causing feeding problems. Enteral nutrition was started by nasogastric tube feeding and a mandibula-extension-therapy was initiated. Due to the mandibula-extension-therapy, general motor development was difficult to assess. However, at 3 months of age the propositus showed decreased muscular tone of his trunk. After extension of the mandibula, the patient was still not able to drink his meals, leaving him on nasogastric tube feeding. Despite adequate caloric intake, he showed failure to thrive. Distinctive features and measures at the corrected age of 3 months were: weight 3,960 $\mathrm{g}(<3 \mathrm{rd}$ percentile), length $55 \mathrm{~cm}$ ( $<3 \mathrm{rd}$ percentile), head circumference $36.1 \mathrm{~cm}$ ( $<3$ rd percentile), high prominent forehead, flat occiput, large fontanelle, wide sagittal suture, hypotelorism, ptosis, blepharophimosis, high nasal bridge, long philtrum, retrognathia, low set ears, sacral dimple, and cutaneous albinism. Finally, he was discharged at 5 months of age. At 10 months of age, we received a notice from his parents that he had died at home due to pulmonary aspiration.

Another Case of Trisomy 6p and Partial Monosomy 20p

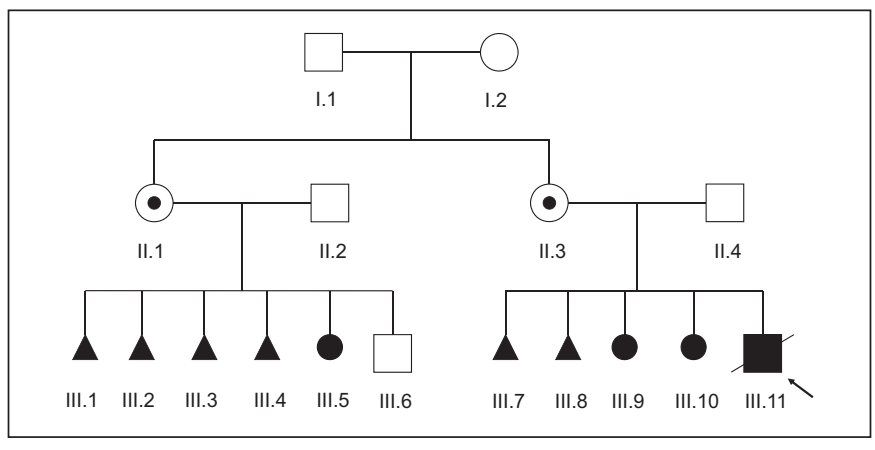

Fig. 1. Pedigree of the presented family.
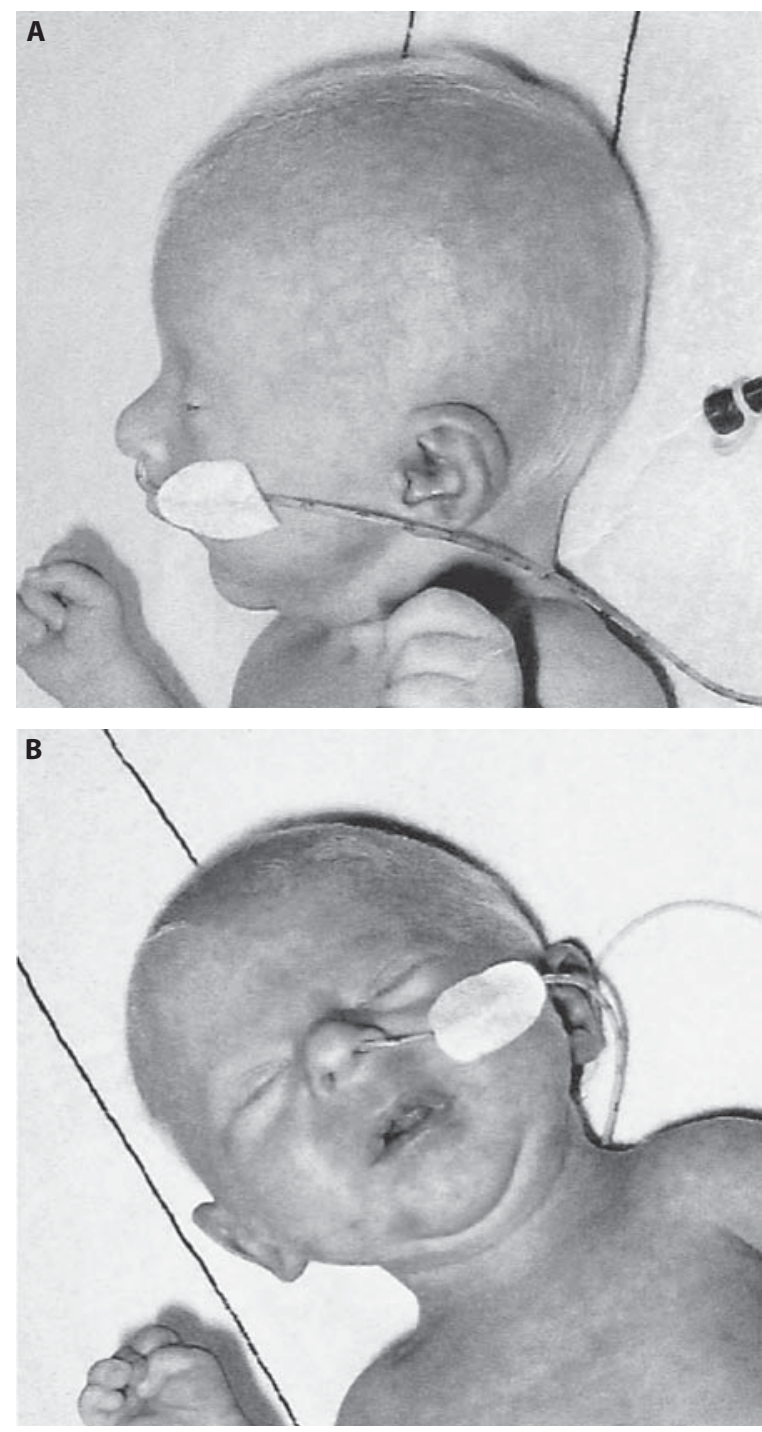

Fig. 2. A Lateral view of the propositus at the age of 3 months, revealing his severe ptosis, retrognathia, low set ears and fair hair and skin. B On the front view of the propositus, his hypotelorism and ptosis become obvious.

Cytogenet Genome Res 2012;136:308-313 
A<smiles>[TeH]</smiles>
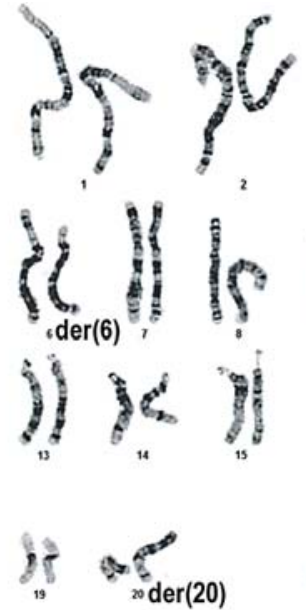<smiles>[131IH]</smiles>

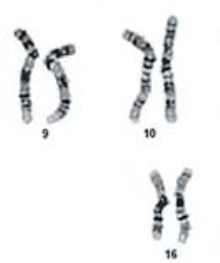

然

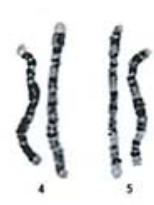

然
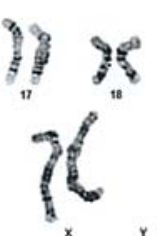

B
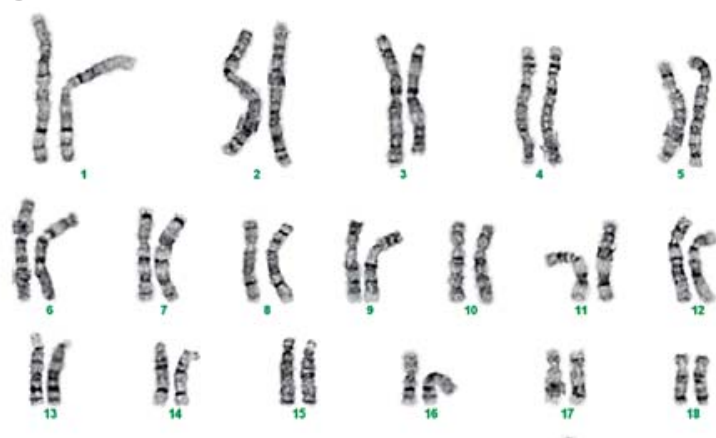

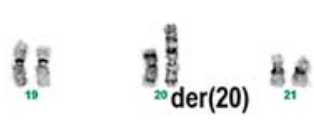

As

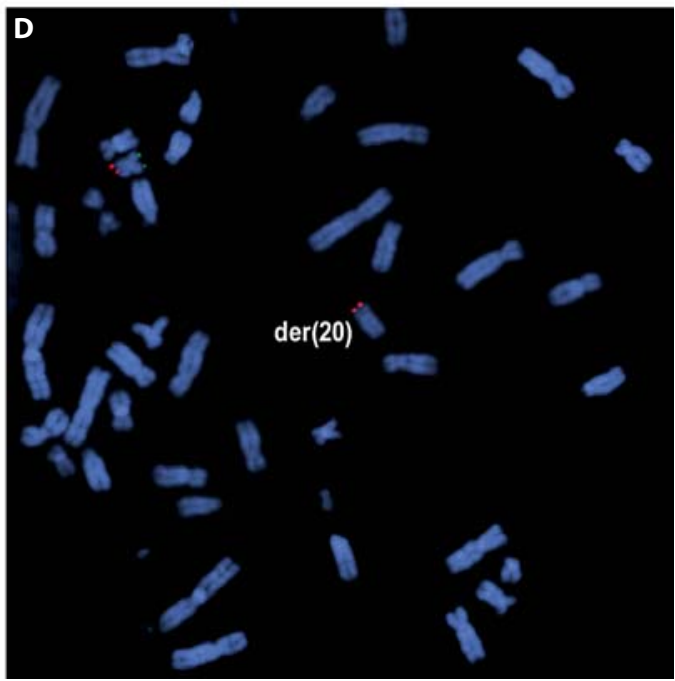

Fig. 3. A GTG-banding of peripheral blood lymphocytes from the patient's mother (II.3) reveals a balanced translocation $\mathrm{t}(6 ; 20)$ (p21.3;p13), i.e. her karyotype contains 2 derivative chromosomes (derivative 6 (der6) and derivative 20 (der20)) and is balanced. B GTG-banding of peripheral blood lymphocytes shows an unbalanced karyotype in the patient (III.11): 46,XY,der(20)t $(6 ; 20)$ (p21.3;p13). The unbalanced translocation results in a partial trisomy 6 p, because 2 normal homologs of chromosome 6 are present in addition to the der(20) containing $6 \mathrm{p}$ material in the short arm, and in a partial monosomy $20 \mathrm{p}$, because terminal 20p is de- leted in der(20). C Visualization of partial trisomy $6 \mathrm{p}$ by 2 -color FISH-analysis with whole chromosome paint probes for chromosome 6 (green) and chromosome 20 (red). In addition to the 2 normal homologs of chromosome 6 , the $\operatorname{der}(20)$ is partially painted (green). Thus, additional chromosome 6 material is located in the short arm of the derivative chromosome 20. D Visualization of the partial monosomy 20p by 2-color FISH-analysis with specific probes for the subtelomeres of the long arm (red) and the short arm (green) of chromosome 20. The der(20) does not have a green signal indicating that there is a terminal deletion of $20 \mathrm{p}$.

\section{Results}

\section{Cytogenetic Studies}

Karyotyping based on GTG-banding at the 500 bands per haploid genome level was performed using standard methods on metaphase spreads from peripheral blood lymphocytes. Karyotyping in the mother revealed

a balanced translocation $\mathrm{t}(6 ; 20)(\mathrm{p} 21.3 ; \mathrm{p} 13)$ (fig. 3A). Pre- and postnatal karyotyping in the patient showed an unbalanced translocation resulting in trisomy $6 \mathrm{p} 25-\mathrm{p} 21.3$ and partial monosomy 20p13 [46,XY, $\operatorname{der}(20) t(6 ; 20)(\mathrm{p} 21.3 ; \mathrm{p} 13) . i s h \quad \operatorname{der}(20) \mathrm{t}(6 ; 20)(\mathrm{p} 21.3 ; \mathrm{p} 13)$ (wcp6+,wcp20+,D20S1157-)] (fig. 3B-D). A chromosomal analysis of the father was normal. 
Table 1. Clinical features reported in 6 patients with partial trisomy $6 \mathrm{p}$ and partial monosomy $20 \mathrm{p}$ resulting from an unbalanced adjacent-1 segregation of translocation $\mathrm{t}(6 ; 20)(\mathrm{p} 21 ; \mathrm{p} 13)$

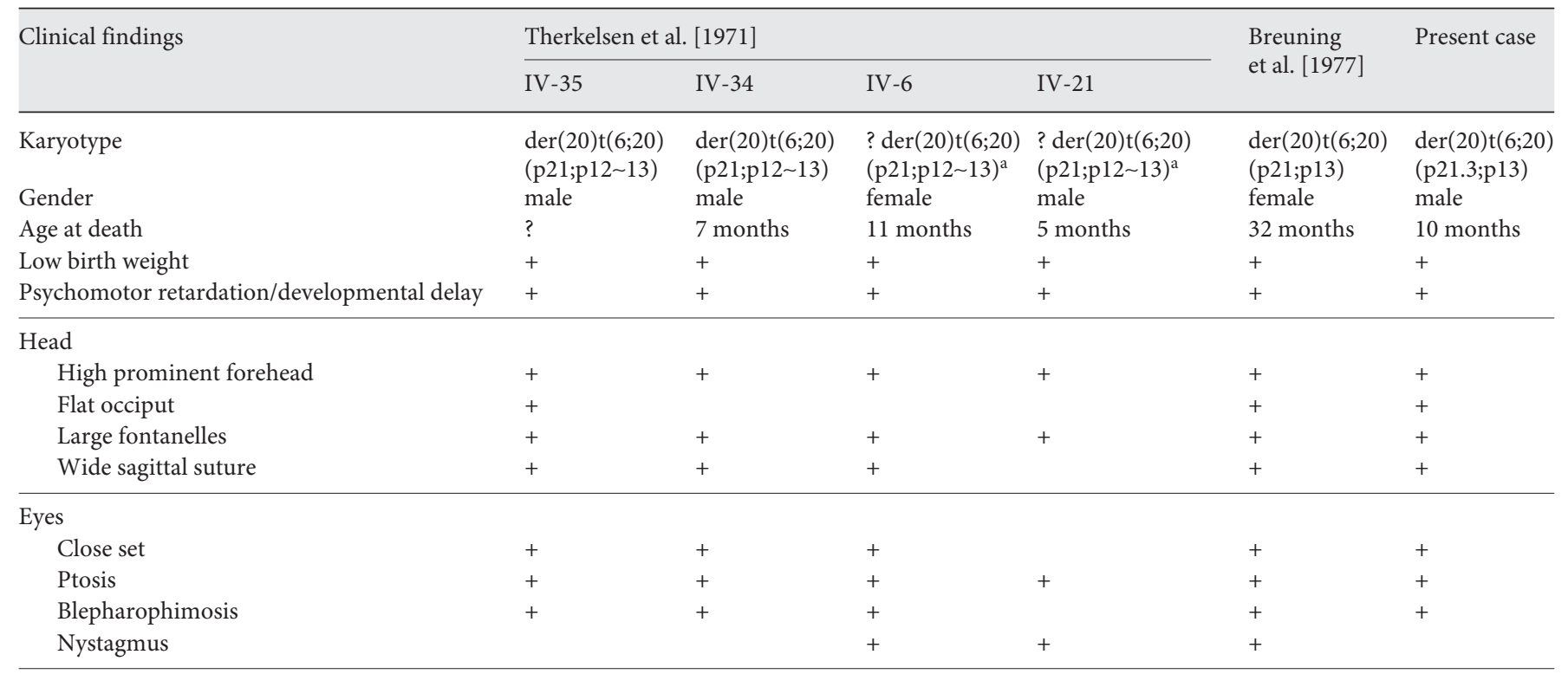

Nose

\begin{tabular}{|c|c|c|c|c|c|c|}
\hline High nasal bridge & + & + & & & & + \\
\hline \multicolumn{7}{|l|}{ Mouth } \\
\hline Small mouth (microstomia) & + & + & + & & & + \\
\hline \multicolumn{7}{|l|}{ Ears } \\
\hline Low set and/or malformed & + & + & + & + & + & + \\
\hline \multicolumn{7}{|l|}{ Skin } \\
\hline Sacral dimple & & & & & + & + \\
\hline Capillary angioma & & + & & & + & \\
\hline Fair skin & & & & & + & + \\
\hline \multicolumn{7}{|l|}{ Heart } \\
\hline Bicuspid aortic and/or pulmonary valve & & & & + & + & \\
\hline Atrial septal defect/ventricular septal defect & + & + & & & + & + \\
\hline Ventricular hypertrophy & & + & & & + & \\
\hline \multicolumn{7}{|l|}{ Lung } \\
\hline Abnormal lobation & & & + & & + & \\
\hline Kidneys & & & & & & + \\
\hline Small kidneys & + & + & + & + & + & + \\
\hline Proteinuria & + & + & + & & + & + \\
\hline \multicolumn{7}{|l|}{ Brain } \\
\hline Chronic meningitis with fibrosis & & & & + & + & \\
\hline Recurrent infections (gastrointestinal, respiratory & + & + & + & & + & + \\
\hline
\end{tabular}

a The 2 cousins IV-6 and IV-21 had already died at the time of family assessment. Hence, partial trisomy $6 \mathrm{p}$ and partial monosomy $20 \mathrm{p}$ could not be confirmed in these cases. 


\section{Discussion}

Therkelsen et al. [1971] described a large Danish kindred with a balanced translocation between $\mathrm{C}$ and $\mathrm{F}$ group chromosomes and 4 family members with an apparently unbalanced karyotype. These 4 family members had various congenital anomalies and severe developmental delay. Although it seems likely that all 4 had the same underlying chromosomal anomaly, the unbalanced chromosomal translocation was only confirmed in 2 of them, because the other 2 children had died before cytogenetic studies could be performed. The identified unbalanced translocations were segregants of a familial translocation $\mathrm{t}(6 ; 20)(\mathrm{p} 21 ; \mathrm{p} 12 \sim \mathrm{p} 13)$ resulting in partial trisomy $6 \mathrm{p}$ and partial monosomy $20 \mathrm{p}$ [Breuning et al., 1977]. Breuning et al. [1977] described a girl who also had partial trisomy $6 \mathrm{p}$ and partial monosomy $20 \mathrm{p}$ resulting from a familial translocation $\mathrm{t}(6 ; 20)(\mathrm{p} 21 ; \mathrm{p} 13)$. In table 1 we present an overview of the phenotypic spectrum found in the 5 previously described cases with partial trisomy $6 \mathrm{p}$ and partial monosomy $20 \mathrm{p}$. All patients overlap with respect to the following features: low birth weight, general psychomotor retardation, high prominent forehead, large fontanelles, ptosis, low set or dysmorphic ears, small/hyperechogenic kidneys and congenital heart defects. Furthermore, it seems that fair skin, blepharophimosis, wide sagittal sutures, cerebral anomalies (chronic meningitis and fibrosis), proteinuria, recurrent pulmonary infections, and death within the first 3 years of life are associated with this unbalanced karyotype (table 1). Hence, the only viable unbalanced karyotype reported for the rare familial translocation $\mathrm{t}(6 ; 20)(\mathrm{p} 21 ; \mathrm{p} 13)$ has been an adjacent-1 segregation resulting in partial trisomy $6 \mathrm{p}$ and partial monosomy $20 \mathrm{p}$, which was last reported on in 1977; however, the underlying translocation $\mathrm{t}(6 ; 20)(\mathrm{p} 21 ; \mathrm{p} 13)$ continues to be transmitted in the population.

In our study, we describe the 6th case with partial trisomy $6 \mathrm{p}$ and partial monosomy $20 \mathrm{p}$ originating from a familial $t(6 ; 20)(\mathrm{p} 21 ; \mathrm{p} 13)$ translocation. We demonstrate striking phenotypic overlap between all cases described here and in the literature (table 1). To perform genetic counseling of translocation carriers at the highest possible level, thorough clinical descriptions of postnatal outcome are required, but particularly difficult to obtain for rare occurrences. Hence, the present synopsis of postnatal symptoms in partial trisomy $6 \mathrm{p}$ and partial monosomy 20p will prepare parents and physicians for the spectrum of postnatal complications that may arise in this condition.
Many of the common phenotypic features of the patients discussed herein might be attributable to partial trisomy of chromosomal bands 6p25-p21. Cardinal features associated with trisomy $6 \mathrm{p} 25-\mathrm{p} 21$ are pre- and postnatal growth retardation, microcephaly, high forehead, hypotelorism, ptosis, blepharophimosis, long philtrum, low set ears, hypoplastic kidneys, congenital heart defects, and recurrent episodes of infections [Schinzel, 2001]. Like the index case with partial trisomy $6 p$ and partial monosomy 20p reported on here, more than half of the cases with partial trisomy $6 \mathrm{p}$ died within their first year of life [Schinzel, 2001].

Deduced from 3 reports encompassing 7 cases, terminal deletion in chromosomal band 20p13 appears to be associated with prominent forehead, large fontanelles, ear abnormalities, congenital heart defects, mental retardation/developmental delay, and failure to thrive [García-Cruz et al., 1985; Anad et al., 1990; McGill et al., 2010]. Furthermore, one of the cases described by Anad et al. [1990] showed a duplex right kidney with bilateral mild to moderate vesicoureteral reflux. Renal biopsy performed at the age of 10 months showed sclerosed glomeruli, tubular atrophy, and calcification. Hence, several symptoms of the patients with partial trisomy $6 \mathrm{p}$ and partial monosomy 20p described and reviewed here might also be attributed to haploinsufficiency of genes located in $20 \mathrm{p} 13$.

In summary, although the presented unbalanced translocation resulting in partial trisomy $6 \mathrm{p}$ and partial monosomy $20 \mathrm{p}$ is extremely rare, the patients summarized here exhibit some similar physical characteristics allowing a fairly good estimate of the postnatal outcome in future cases diagnosed prenatally.

\section{Acknowledgements}

H.R. is a member of the 'Network for Systematic Investigation of the Molecular Causes, Clinical Implications, and Psychosocial Outcome of Congenital Uro-Rectal Malformations (CURE-Net)' and is supported by a research grant (01GM08107) from the German Federal Ministry of Education and Research (Bundesministerium für Bildung und Forschung, BMBF). We wish to thank Dr. Dieter Meschede and Dr. Regine Schubert (Clinic for Human Genetics, Cologne) for the cytogenetic analysis of family member II.4. 


\section{References}

Anad F, Burn J, Matthews D, Cross I, Davison BCC, Mueller R, Sands M, Lillington DM, Eastham E: Alagille syndrome and deletion of 20p. J Med Genet 27:729-737 (1990).

$\checkmark$ Breuning MH, Bijlsma JB, de France H: Partial trisomy $6 \mathrm{p}$ due to a familial translocation $\mathrm{t}(6 ; 20)(\mathrm{p} 21 ; \mathrm{p} 13)$. A new syndrome? Hum Genet 38:7-13 (1977).
García-Cruz D, Rivera H, Barajas LO, JiménezSáinz M, Nazará Z, Sánchez-Corona J, Durón-Huerta H, García-Ochoa C, Cantú JM: Monosomy 20p due to a de novo del(20) (p12.2). Clinical and radiological delineation of the syndrome. Ann Genet 28:231-234 (1985).

McGill AK, Pastore MT, Herman GE, Alliman S, Rosenfeld JA, Weaver DD: A tale of two deletions: a report of two novel $20 \mathrm{p} 13 \rightarrow$ pter deletions. Am J Med Genet A 152A:1000-1007 (2010).
Oliver-Bonet M, Navarro J, Carrera M, Egozcue J, Benet J: Aneuploid and unbalanced sperm in two translocation carriers: evaluation of the genetic risk. Mol Hum Reprod 8:958-963 (2002).

Schinzel A: Catalogue of Unbalanced Chromosome Aberrations in Man, 2nd edition (De Gruyter, Berlin 2001).

Therkelsen AJ, Klinge T, Henningsen K, Mikkelsen M, Schmidt G: A family with a presumptive C-F translocation in five generations. Ann Genet 14:13-21 (1971). 